\title{
A Sangue Frio: jornalismo diversional em Truman Capote
}

\section{In Cold Blood: Diversionary Journalism in Truman Capote}

DOI: 10.46814/lajdv3n2-025

Recebimento dos originais: 23/12/2020

Aceitação para publicação: 26/02/2021

\author{
Sandro Lauri da Silva Galarça \\ Doutor em Teoria Literária. \\ Universidade Regional de Blumenau, FURB \\ E-mail: sandro.galarca@gmail.com
}

\begin{abstract}
RESUMO
O presente artigo apresenta uma síntese da tese de doutorado intitulada Sujeito, discurso e delinquência - uma cartografia de A Sangue Frio, em que se apresenta uma análise sobre os signos narrativos que constroem os sujeitos na obra A Sangue Frio, de Truman Capote. Procura-se evidenciar como o jornalismo diversional se utiliza do discurso acerca dos sujeitos - ambiente, comportamento, vestimentas, características destas personagens ou, a rigor, a personalidade dos envolvidos - mas também como é constituído o sujeito que emerge do discurso. Para tanto, esta obra será lida pela lente do pensamento de Michel Foucault e de seu entendimento sobre a construção dos sujeitos a partir da narrativa que se forma sobre ele. O artigo está sustentado por um questionamento central: quem é esse sujeito constituído não a partir de seu ato, mas pelos enunciados que narram suas causas e consequências?
\end{abstract}

Palavras-chave: Jornalismo Diversional, Discurso, Delinquência, Truman Capote, Michel Foucault.

\begin{abstract}
The present article presents a summary of the doctoral thesis entitled Subject, discourse and delinquency - a cartography of In Cold Blood, which presents an analysis of the narrative signs that construct the subjects in the work In Cold Blood, by Truman Capote. The aim is to show how diversionary journalism uses discourse about the subjects - the environment, behavior, clothing, characteristics of these characters or, strictly speaking, the personality of those involved - but also how the subject that emerges from the discourse is constituted. To this end, this work will be read through the lens of Michel Foucault's thought and his understanding of the construction of subjects from the narrative that is formed about them. The article is sustained by a central questioning: who is this subject constituted not from his act, but from the statements that narrate his causes and consequences?
\end{abstract}

Keywords: Diversionary Journalism, Discourse, Delinquency, Truman Capote, Michel Foucault.

\section{INTRODUÇÃO}

O cenário de uma prisão é um ambiente suficientemente conhecido: grades de ferro com tinta descascada, correntes, cadeados e um som metálico abafado a cada passagem de pavimento. As janelas, quando existem, são pequenas aberturas, normalmente em forma de quadrado e dispostas bem acima das cabeças dos detentos, reforçadas com grossas barras de ferro. As referências de cama, banheiro, refeitório e lazer que se tem da vida do lado de fora são muito diferentes do que as instalações de um 
presídio oferecem: são acanhadas, mal cuidadas e a padronização do atendimento só leva em consideração a segurança do local e a garantia de que nenhum habitante deste espaço terá sua fuga facilitada.

Quem está preso neste ambiente normalmente tem uma visão mais reduzida das instalações precárias e do aparato de segurança montado à sua volta e, em contrapartida, suas representações parecem-lhes mais significativas. A segurança se apresenta maior do que realmente é e, com o passar do tempo, indivíduos e ambiente entram numa simbiose involuntária, de maneira que se torna praticamente impossível separar quem é um e quem é outro. $\mathrm{O}$ ambiente molda o homem e o indivíduo acaba envolvido pelo estereótipo: como resistir à força de um assujeitamento de tais proporções? O isolamento que lhe retira do convívio social atinge não somente o corpo, mas pune também a alma: priva-o da liberdade, reduz seus direitos ao confinamento e caça-lhe o livre-arbítrio, uma vez que é o Estado quem decide seu futuro, as roupas que veste, a alimentação do dia, as horas do sono e o nível de sua qualidade devida.

Dois exemplos clássicos dessa literatura oferecem um corte longitudinal, tanto do sistema carcerário quanto na questão da punição, para dar lugar a uma discussão sobre a história dos sujeitos e, por assim dizer, dos atores deste universo. Cada um a seu modo, o texto de A Sangue Frio, de Truman Capote (1980), e Vigiar e Punir, de Michel Foucault (2004), perpassam suas observações sobre uma ampla discussão sobre a punição. O ponto principal deste artigo é ressaltar a discussão proposta, tanto num como noutro: analisar os elementos presentes nos textos em questão e que levam à construção ficcional de um discurso que põe em suspensão a construção do universo simbólico em que se dá a relação entre os sujeitos e a própria constituição ficcional desses sujeitos.

Em A Sangue Frio, Truman Capote apresenta várias faces de um sistema penitenciário padronizado, as sutis diferenças dentro de um grande organismo e as particularidades de sua população carcerária, numa tentativa de questionar o estereótipo amplamente trabalhado nos meios de comunicação. O livro conta a história de quatro membros de uma mesma família, brutalmente assassinada em uma fazenda no interior de Holcomb, Oeste do estado do Kansas, EUA, a partir de uma narrativa que busca, em um primeiro momento, dar ao conhecimento os dois autores dos assassinatos. $\mathrm{Na}$ escritura de Capote, não é tão importante entender como ou por que o crime foi cometido, mas por quem. Aqui, o sistema prisional norte-americano é descrito com status de personagem e os elementos cênicos expostos na narrativa acabam compondo um amplo cenário desde a pacata cidade onde o crime acontece até os corredores que levam os condenados à morte por enforcamento.

Importante destacar que a referida obra pertence ao que se convencionou chamar de New Journalism, sendo mais do que um simples exemplar, mas um livro emblemático e que marcou uma geração inteira de escritores norte-americanos. Destarte, o New Journalism assume um local de 
destaque no que ele chama de Jornalismo Diversional, gênero jornalístico que tem como marcas a presença do narrador em primeira pessoa, o texto de natureza mais impressionista e as múltiplas vozes narrativas que se cruzam fortuitamente. Além de Capote, pode-se inserir neste contexto autores como Norman Mailer, Gay Talese, Tom Wolfe e Joseph Mitchels. A importância deste momento literário americano pode ser creditada ao fato de que, ao invés de a literatura criar um romance a partir do cotidiano, é o cotidiano que começa a ser desnudado pelos traços literários. (WOLFE, 2005).

\section{SUJEITO E PODER}

A presente análise pretende debruçar-se sobre os signos que constroem não somente o universo semântico em que se dá a instituição da prisão, assim como a punição e também o controle - o ambiente, o comportamento, as roupas, as características destas personagens ou, a rigor, a personalidade dos envolvidos - mas também como é constituído o sujeito que emerge deste discurso em A sangue Frio. Para isso, esta obra será lida pela lente do pensamento de Michel Foucault e de seu entendimento sobre a construção dos sujeitos a partir da narrativa que se forma sobre ele. Assim, tornase necessário aceitar que Foucault não só pensa, mas parte da existência de uma dualidade que põe, de um lado, a forma representada pela visibilidade da prisão; e de outro, o conteúdo composto pelos enunciados, que dão sustentação às punições em si, pela autenticidade encontrada no direito penal e pela legitimação de um sistema de punições por meio de um discurso "oficial” sobre a delinquência.

Interessante observar a clássica diferenciação que Foucault faz ao longo de seu trabalho sobre os termos subjetivação e assujeitamento. De acordo com Revel (2005), o termo "subjetivação" designa, para Foucault, um processo pelo qual se obtém a constituição de um sujeito, ou mais exatamente, de uma subjetividade. Continua a autora:

\footnotetext{
Os "modos de subjetivação" ou "processos de subjetivação" do ser humano correspondem, na realidade, a dois tipos de análise: de um lado, os modos de subjetivação que transformam os seres humanos em sujeitos - o que significa que há somente sujeitos objetivados e que os modos de subjetivação são, neste sentido, práticas de objetivação; de outro lado, a maneira pela qual a relação consigo, por meio de um certo número de técnicas, permite constituir-se sujeito de sua própria existência. (2005,p.82)
}

A noção de assujeitamento, bem conhecida dos primeiros trabalhos de Foucault, reaparece nos seus últimos textos. O termo é utilizado para a influência de poderes normalizantes sobre os indivíduos, dos quais resultam sujeitos produzidos ou fabricados. Em algumas traduções, o termo "subjetivação" aparece no lugar de "assujeitamento", o que remete a resultados bastante diferentes. Isso porque o próprio Foucault usa o termo francês "subjectivation", tradução que resulta em uma ambiguidade entre este termo e "assujettissement", que traz na sua gênese o aspecto dominante de submeter-se a, subjeção, 
ou ainda subjugação, tanto quanto um tirano reinante sobre seus sujeitos, como esclarece Harrer (2005, p. 79) ${ }^{1}$.

Em Narrar ou descrever? Lukács (1965) põe a experiência no centro do romance. Para ele, o método da narração ou da descrição deságuam em uma única finalidade: descobrir os traços atuais e significativos de uma práxis social. Para o autor, quem estaria no centro dessa práxis senão o homem? Dessa forma, justifica que os personagens são a coisa principal da narrativa e o movimento dos acontecimentos servem apenas para introduzir os personagens como tais em um jogo naturalmente atraente.

\begin{abstract}
Não ocorre, pois, que eles estejam em cena apenas para ajudar a manter o movimento. O fato é que o autor torna interessante aquilo que precisa ser tornado, enquanto o que é interessante por si mesmo fica entregue às suas próprias forças... Os personagens constituem sempre o principal. E, na realidade, um acontecimento - por maravilhoso que seja - não nos interessa a longo prazo tanto como os homens aos quais nos afeiçoamos com a convivência. (LUKÀCS, 1965, pág. 61)
\end{abstract}

A tensão de um romance, para Lukàcs, não se explica pelo valor estético e pelas soluções encontradas pelo autor para concluir a narrativa, mas pela curiosidade tipicamente humana de saber que iniciativas tomarão os personagens centrais e que obstáculos deverão ainda superar para chegar ao objetivo que já conhecemos. Em A Sangue Frio, o leitor conhece os assassinatos de que são acusados Perry e Dick. É um fator a ser destacado, também, que já nas primeiras páginas o leitor é informado da autoria atribuída a ambos. Portanto, o mérito da ficção no romance nem sempre se dá ao ineditismo da história, mas à explicação detalhada de como essa história aconteceu a partir da narrativa focada em seus atores.

Pode-se aproximar o pensamento de Lukács ao de Michel Foucault no que diz respeito ao efeito das relações de poder. Para Lukács, a essência corpórea do homem também só adquire vitalidade na relação com outros homens, na influência que exerce sobre eles. Em Foucault, entendemos que toda influência exercida é também uma relação de poder. $\mathrm{O}$ autor nunca trata do poder como uma entidade coerente, unitária, estática, mas sempre de relações de poder que supõem condições históricas de emergências complexas e que implicam efeitos múltiplos, compreendidos fora do que podemos denominar de campos do poder.

\title{
3 OS DISCURSOS SOBRE OS SUJEITOS
}

\footnotetext{
${ }^{1} \mathrm{Na}$ tese de doutoramento que dá origem a este artigo, ambos os termos são empregados, mas cada um com sua finalidade e significado. Por subjetivação determinaremos os processos institucionais que constituem o sujeito numa relação multilateral a partir do poder exercido indiretamente sobre ele. Por assujeitamento, entenderemos os momentos em que essa relação de dependência ao poder formalizado e tangível puder ser verificada de modo direto.
} 
Para chegar à questão de como é formado o universo discursivo sobre o sujeito, precisamos conceituar, primeiro, universo discursivo como o conjunto das práticas - verificadas na escrita e fora dela - e que compõem uma narrativa sobre alguém. Fazem parte deste universo discursivo algumas unidades de discurso - a língua, expressões idiomáticas, figuras de linguagem, adjetivos, interjeições, verbos de ação e, ainda elementos discursivos, que vão desde a própria utilização de um texto narrativo, a descrição do espaço e dos personagens, um ponto de vista do autor com caráter mais dissertativo, as informações colhidas durante o processo de apuração e sua justaposição lógica etc.

Todos os motivos acima elencados têm como ponto de vista o olhar do narrador. É sua a avaliação final sobre a história que vai contar. Que sentido ela vai ter ao ser contada, registrada? Como será entendida no infinito universo de relações simbólicas que podem ser estabelecidas a partir de uma simples sucessão de eventos? Se ele parte de uma descrição de um personagem que, em si, possui o interesse enquanto signo representativo, importante dentro da história, tem mais apelo na hora de ilustrar as histórias que vive e que, por condução, vão sendo narradas. Quanto mais interessante é o personagem, maior a identificação com a audiência.

Entretanto, o resultado do uso dessa literatura começou a ter uma dimensão diferente daquela intencionada pela justiça. Muitas vezes, o condenado se tornava herói pela enormidade de seus crimes largamente divulgados e até em virtude de seu arrependimento. Como a maioria dos crimes era cometido contra a propriedade - leia-se contra os ricos ou contra o pagamento de impostos ao governo - o criminoso aparecia como alguém que tivesse travado um combate em que todos se reconheciam facilmente (FOUCAULT, 1997, pág. 55). A proclamação póstuma dos crimes justificava a justiça, mas também glorificava o criminoso, o que leva os relatos sobre os crimes a apagarem a figura do criminoso como herói.

Historicamente, a partir deste momento, é dado ao discurso formal a força de um discurso único, incorruptível. O modelo não oferece brechas para que se leve em consideração uma narrativa que dê conta da questão anterior: quem é este indivíduo que cometeu este crime? Isso se explica facilmente pelo apelo estético encontrado pelo modelo de criminoso fabricado ao longo da história. A descrição sobre o criminoso modelo gira em torno de um eixo conhecido e reproduzido à exaustão: está numa classe social menos favorecida economicamente, numa situação de marginalização, vive na periferia e goza de um poder entre seus pares.

Em A vida dos homens infames, Michel Foucault trata de reunir o que ele chama de uma "antologia de existências". Buscando sempre a mão inversa do que o discurso da delinquência apresenta, Foucault recupera algumas histórias encontradas por acaso em livros e documentos. O autor argumenta que o termo "notícia" seria bastante conveniente, uma vez que indica uma dupla referência: a rapidez do relato e a realidade dos acontecimentos relatados. Desta forma, Foucault atenta para a 
condensação do que é dito nestes textos, ressaltando que não se sabe "se a intensidade que os atravessa deve-se mais ao clamor das palavras ou à violência dos fatos que nele se encontram" (FOUCAULT, 1994, pág. 204).

O que interessa a Foucault é o tratamento dado a essas vidas, resumidas em algumas "frases em torno de personagens sem dúvidas miseráveis, ou com os excessos, a mistura de obstinação sombria e de perfídia dessas vidas das quais se sentem, sob as palavras lisas como a pedra, a derrota e o afinco". (FOUCAULT, 1994, pág. 204). Foucault explica a tentativa de saber um pouco mais por que, de repente, tinha sido tão importante a uma sociedade como a francesa que um monge escandaloso ou um agiota extravagante e inconsequente fossem "sufocados", como se sufoca um grito, um fogo ou um animal.

Assim, Foucault questiona, a que serve esse discurso, se não é útil para que se conheça nem os condenados, nem a relação que mantinham com a sociedade, nem o crime de modo mais aprofundado? A que ou a quem serve este discurso se não à manutenção das relações de saber hierárquico, concentrador das estratégias de poder de punição e, mais ainda, de projeção de uma exemplaridade na sociedade?

Pode-se dizer que é justamente isso que faz Truman Capote em A Sangue Frio, ao focar sua observação para um crime aparentemente simples, cometido por pessoas comuns e que seriam, seguramente, invisíveis à sociedade americana e à Justiça. Ao ler dez linhas sobre o assassinato da família Clutter numa página interna do jornal The New York Times, em novembro de 1959, Capote sentiu a mesma necessidade que Michel Foucault teve em buscar conhecer e demonstrar quem são esses indivíduos que já tinham seus destinos traçados.

Em A Sangue Frio, a primeira aparição dos dois assassinos é de Perry Smith, que de acordo com a descrição de Capote está sentado em uma lanchonete de Kansas City, bebendo root beer - uma bebida de pequeno teor alcoólico, feita de extrato de raízes - acompanhada de aspirinas e cigarro, enquanto aguarda impaciente seu amigo Dick. No texto de Capote, uma suave ligação entre os dois ambientes - a narrativa deixa as descrições da fazenda e os enunciados que dão conta de como vive o personagem Herbert Clutter e, por extensão, como é a vida da família para focar em Perry Smith - tem o efeito da transição entre dois mundos, um ponto de toque entre as histórias que correm paralelas, mas que estão prestes a se encontrar:

Assim como o Sr. Clutter, o rapaz sentado na lanchonete Little Jewel não tomava café. Preferia root beer. Três aspirinas, root beer gelada e um cigarro Pall Mall após outro: refeição era isso. Bebericando e fumando, estudava um mapa aberto à sua frente, no balcão (um mapa Phillips 66 de México), mas era difícil concentrar-se, pois esperava um amigo e o amigo estava atrasado. (pág. 18) 
A aproximação torna-se necessária, em primeiro lugar, porque cumpre a função de esclarecer a metodologia de alternância em que a história é narrada. Trata-se de dar as regras do jogo na primeira vez que esse método é apresentado, uma vez que o texto deixa a narrativa inicial que contém as descrições de Holcomb e de River Valley Farm e o que acontece com seus personagens e passa a tratar sobre o outro foco narrativo, cuja presença da dupla Perry Smith-Dick Hickock é fundamental para o desenrolar dos acontecimentos.

A escolha do hábito de não tomar café da manhã como elo entre os dois ambientes - embora seus protagonistas tenham personalidades completamente diferentes - acaba por humanizar o discurso e evitar que o excesso de descrições afaste o texto de seu propósito: de um primeiro momento comparativo para a construção dos personagens por oposição. Interessante notar a referência que é feita aos dois personagens, na tentativa de traçar um paralelo de aproximação. Enquanto Herbert Clutter é tratado como Sr. Clutter, Perry Smith ganha apenas a descrição de "o rapaz sentado na Lanchonete Little Jewel”.

Seria a referência a um sujeito sem rosto, como todos os ex-presidiários? Um sujeito que serve à narrativa, mas que ainda não está em condições de subvertê-la? Um sujeito em construção e, por isso mesmo, incompleto? Essas especulações são úteis quando nos questionamos a respeito do que se pretende mostrar e, mais, do que está para ser visto. Apresentar Perry dessa forma acaba atraindo para a narrativa, e não para o personagem, um status tal que o discurso que se faz dele é perfeitamente entendido. Linguagem de subjetividades, é por meio das referências diretas e indiretas que acreditamos que Perry Smith será melhor apresentado posteriormente e que ele vai interagir com outro personagem, a quem aguarda com ansiedade. Na construção deste trecho, Capote revela aos poucos por que esse encontro é tão importante para a narrativa, e o faz numa perspectiva que essa importância é atribuída pelo próprio personagem em questão.

Um elemento útil a este propósito é o discurso proveniente da consciência de Perry. A narrativa aponta para uma sucessão de eventos que ligam este ponto específico na narrativa ao passado e ainda sugerem uma relação de futuro. Nota-se claramente que esta descrição, esta construção cênica e de acontecimentos marca um evento fundamental para o desenvolvimento de toda a narrativa. Nestas linhas, a consciência de Perry passeia pelos mapas cuidadosamente abertos no balcão e, do mesmo modo, explicam por que ele está ali.

Este momento do texto sintetiza os eventos por meio de uma economia narrativa. Neste diálogo subjetivo que Perry trava com sua consciência, descobrimos o plano sobre o crime, aqui chamado de "golpe" (aspas do autor) e começamos a fazer a ligação entre as histórias paralelas, assim como somos apresentados aos atores da narrativa e ao cenário que serve de palco para a ação: 
Agora, graças a uma carta, um convite para um "golpe", ali estava com tudo o que tinha no mundo: uma mala de papelão, um violão e duas caixas de livros, mapas e canções, poemas e cartas velhas, pesando quase duzentos e cinqüenta quilos. (...) Aqui estava na pequena cidade de Olathe, no Kansas. Gozado, pensar nisso. Imagine: de volta ao Kansas. Quatro meses antes jurara, primeiro à Comissão Estadual de Livramento Condicional, depois a si próprio, nunca mais botar os pés no Estado. Não demorara muito. (pág.19)

Depois que se tem certeza de que a história está sendo conduzida por Perry, algumas descrições físicas servem para qualificar melhor o sujeito dos acontecimentos. O modo de apresentar essas características acaba por revelar um homem diferente da maioria, cujas particularidades revelam um pouco de seu passado e auxiliam a compor o quadro que se pinta sobre o primeiro dos assassinos a ser introduzido na história. Diz a descrição de Capote que Perry quando era visto sentado parecia maior que o comum, "um homenzarrão vigoroso, com ombros, braços e dorso atarracados de levantador de peso" (pág.19). No entanto, ao se pôr em pé, o que se via era um corpo desproporcional. Esta é a descrição que dá uma noção melhor da figura humana que Perry representava:

Os pés pequenos, em botas pretas curtas, com fivelas de aço, caberiam nas sapatilhas de dança de uma garota delicada. Quando ficava em pé, tinha a altura de um menino de doze anos e, arrastando-se com pernas inadequadas e grotescas para o volume do corpo que suportavam, mais parecia um jóquei aposentado que um chofer de caminhão. (pág.20)

Impossível não formar uma imagem deste personagem a partir destas descrições. As comparações feitas por Capote nos dão a ideia de que se trata, inclusive, de um personagem caricato. Pela soma das descrições, inclusive, podemos inferir a ele uma tipificação de comportamento, principalmente se recuperarmos a cena anterior, em que bebia root beer na lanchonete. Suas atitudes e seu tipo físico denunciam um paradoxo: parecem reforçar o estereótipo de um ex-presidiário, ao mesmo tempo que o conhecimento mais profundo sugere um tipo sui generis de personagem.

As descrições seguem, mostrando os traços de um rosto volúvel em frente ao espelho. Sua mãe era uma índia cheroqui puro-sangue, de quem herdara a cor da pele, os olhos e os cabelos. De seu pai irlandês tinha apenas lábios rosados e o nariz levemente arrebitado, e o sangue que às vezes dominava o que Capote "chama de máscara de cheroqui" para ilustrar o devaneio de cantar para uma platéia num clube de Las Vegas, sua terra natal. Assim perdia horas, hipnotizado com o público, os aplausos, as interpretações, o cenário noturno, a letra da música de sua própria autoria com que encerraria o espetáculo.

Essas divagações, entretanto, perdiam espaço para outras visões que o acompanhavam desde menino. A coleção de mapas, cursos de mergulho, folhetos, literatura sobre barcos naufragados com verdadeiras fortunas em ouro e joias embalavam o sonho de mergulhar em águas estranhas em direção 
à carcaça de um navio gigantesco, uma carga submersa de diamantes e pérolas, arcas cheias de ouro. Constantemente se pegava no meio de uma conquista deste porte, que mudaria sua vida para sempre. $\mathrm{Na}$ narrativa de Capote, estão justapostas esta cena e a chegada de Dick, como que sua presença interrompesse um sonho, ainda que estivesse acordado. "Um carro buzinou. Enfim: Dick".

A buzina do carro, de modo simbólico, devolve Perry à realidade. Ao mesmo tempo que conhecemos um pouco mais sua personalidade, entendemos também um pouco de seu passado, compreendemos seu desejo de futuro e nos aproximamos um pouco mais de quem é este protagonista. A narração a partir deste ponto mistura os elementos luminosos, como coloca Deleuze (1988), que são aqueles percebidos na visibilidade do personagem e de seus atos, ao conteúdo de suas atitudes, aqui formalizado pelos enunciados de um discurso. Este amálgama não é somente o resultado de uma operação estética, mas a metodologia de uma construção ficcional que recupera a ação dos personagens para oferecer uma realidade a ser conhecida.

A passagem em questão, que talvez só exista no discurso do narrador - o som da buzina desperta Perry de mais um devaneio em busca das riquezas no fundo do mar - materializa-se pela linguagem e sedimenta a parte da narrativa que se está querendo sublinhar. Ainda não se percebe qual a profundidade da relação entre os dois personagens, mas subentende-se que desta união parte uma relação de poder em que forças contrárias irão entrar em conflito, uma vez que toda relação de forças é uma relação de poder. Há uma cumplicidade tácita nesta relação de poder. E o som da buzina une o discurso interno, apegado ao universo de acontecimentos sonhados por Perry, ao discurso externo, no ponto de contato com o ato em si e no retorno à "realidade". A buzina une as duas narrativas, aproxima os dois mundos a partir de um fenômeno que só seria possível no universo do discurso.

Podemos referir que a lembrança dos sujeitos e suas ações acontece essencialmente no campo dos enunciados. Deleuze (1988) salienta este ponto a partir de uma pergunta: qual é a condição mais geral dos enunciados ou das formações discursivas? Para ele, a resposta de Foucault adquire importância por excluir a priori um sujeito da enunciação. O sujeito é uma variável, ou melhor, um conjunto de variáveis de um enunciado. Deleuze complementa, explicando que esta é uma função derivada da primitiva, ou do próprio enunciado. Em Arqueologia do saber, Foucault analisa essa função-sujeito: o sujeito é um lugar ou uma posição que varia de acordo com o tipo, segundo o limiar do próprio ato enunciativo.

É bem provável que as descrições minuciosas apresentadas pelo narrador sejam construções literárias, uma vez que o modo utilizado para se chegar a essas descrições é a recriação do universo a partir dos elementos cênicos. E o que pode-se salientar não são apenas as descrições utilizadas para nos apresentar Dick, mas a intervenção do narrador por meio da ação dos personagens. Em meio a essas descrições, aparece um "Mas certa vez Perry disse: 'o olho não importa. Você tem uma beleza 
de sorriso. Um desses sorrisos que funcionam"”. O que esta referência a Perry representa? Como isso opera no campo do discurso? Que enunciado é dado para ser lido? Em que medida essa expressão atribuída ao amigo representa uma reciprocidade ao "meu anjo" atribuído a Dick, algumas páginas antes?

As descrições que nos apresentam os personagens de modo mais detalhado remetem ou ao universo da prisão em si ou ao universo da marginalidade em que viveram antes do período na prisão. As referências sobre o livramento condicional, os companheiros de cela, ou das passagens que explicam como foram parar na prisão reforçam esse discurso, uma vez que nos dão a entender que sua própria história de vida se explica de certa forma pela coerção exercida pelo discurso que os qualificam.

Vejamos as descrições que o autor começa a fazer sobre Perry, logo na sequência. Começa por dizer que Perry também fora mutilado em um acidente de motocicleta e que os ferimentos tinham sido muito mais graves do que os de Dick. Ao usar o termo "mutilado"2 logo no início do parágrafo, temse um efeito de dimensões mais impactantes do que se ele não estivesse ali ou se, ao contrário, fechasse uma descrição física como uma espécie de conclusão natural pelo próprio contexto.

O fato é que o acidente foi realmente grave e todas as informações que recebemos sobre ele não deixam qualquer dúvida:

Passara seis meses num hospital no estado de Washington e outros seis meses de muletas e, embora o acidente acontecesse em 1952, suas pernas atrofiadas e grossas, partidas em cinco lugares diferentes e dolorosamente marcadas de cicatrizes, doíam tanto que se tornara "viciado" em aspirina. (p. 24)

Um fato que não pode passar despercebido, entretanto, é a consideração de que as referências para Perry apontam sempre para um ex-detento, um sujeito constituído como tal. As marcas do encarceramento podem ser vistas em sua personalidade, nas atitudes, comportamento, traços físicos, enfim, servem para compor a imagem que se pretende imprimir ao sujeito. As descrições e demais passagens que cumprem essa tarefa aparecem, via de regra, numa relação com o ambiente, com o personagem de Dick, ou numa ligação temporal com a cena do crime ou com algum aspecto relacionado ao passado e à prisão anterior.

É como se a vida de Perry se resumisse a atitudes relacionadas à prisão ou a uma conduta criminosa. Isso pode ser facilmente notado quando vemos que as descrições físicas e a narrativa sobre o passado mantêm uma ligação íntima com o acontecimento em questão: o assassinato da família Clutter, a 15 de novembro de 1959. Todos os acontecimentos e os enunciados a respeito destes

\footnotetext{
${ }^{2}$ Originalmente, Capote usa o termo maimed, que também pode ser traduzido como aleijado. O efeito que este termo provoca no leitor ganha uma representação maior do que a realidade, uma vez que se interpreta como invalidez permanente, já que a mutilação está quase sempre ligada à perda de um membro ou à perda total de mobilidade.
} 
acontecimentos apontam para a capacidade que os sujeitos apresentados demonstram de cometer o crime que está sendo construído. Mesmo antes da cena do crime em si, o texto acaba constituindo a criminalidade dos sujeitos. Isso acontece basicamente por dois motivos: primeiro, porque os elementos descritivos de comportamento através da linguagem reforçam o estereótipo do ex-presidiário como se ele ainda fosse um delinquente. Não há um discurso que separe o crime de seu autor, ao contrário, todo o discurso acaba reforçando a ideia da delinquência. É como se o personagem estivesse sempre na iminência de cometer um novo crime, uma espécie de passado como marca indelével de uma conduta esperada.

\section{O SUJEITO CRIMINOSO}

Consideremos que o discurso sobre o criminoso, de acordo com o que vimos até aqui a respeito de subjetividade, seja sempre visto do lado "de fora", a partir do olhar que a sociedade entende historicamente por sujeito marginal. Foucault lembra que o sujeito marginal é aquele explorado em suas particularidades mais universais, porque esse discurso a respeito da criminalidade se apoia em estratégias de poder que normalmente já o colocam como sujeito à marginalidade. Estar colocado à margem, neste caso, pode ser entendido como uma construção social, uma vez que os indivíduos que pertencem "naturalmente" ao grupo social têm certas características que não estão presentes entre os "marginalizados".

Mas, como Foucault trabalha o surgimento do discurso da criminalidade? Para ele, não há um ponto central que emana tal discurso a partir de um único vetor. $\mathrm{O}$ discurso da criminalidade, ao contrário, surge e se desenvolve a partir de redes, teias confeccionadas pelas relações de poder no interior da sociedade. Nesse raciocínio, lembra que no início, no período dos castigos, trabalhado detalhadamente na primeira parte de Vigiar e Punir, alguns criminosos eram tolerados pela população. Não havia uma classe autônoma de delinquentes, e para isso o autor mostra que historicamente alguns deles, como Mandrin ${ }^{3}$, eram bem recebidos pela burguesia, pela aristocracia, bem como pelo campesinato, pelos lugares onde passavam, sendo protegidos por todos. Isso muda com a capitalização. A partir do momento em que a classe popular tem em mãos uma riqueza investida em matérias-primas, máquinas e instrumentos, foi absolutamente necessário proteger essa riqueza. (FOUCAULT, 2004).

\footnotetext{
${ }^{3}$ Mandrin é um conhecido contrabandista francês do século XVIII, famoso por ter fugido pouco antes de sofrer a execução a que fora condenado por uma briga em local público. Foi o líder de 300 contrabandistas armados e organizou seu bando como um verdadeiro regimento militar. No ano de 1754 organizou seis campanhas militares. Ele rapidamente recebeu o apoio do povo local, pois comprava mercadorias como couro, tabaco e especiarias e as revendia a um preço bem mais barato, pois não pagava impostos. Ele foi julgado em 24 de maio de 1755, depois quebrado na roda em Valence, em 26 de maio, diante de 6 mil espectadores, tendo suportado a tortura sem um grito. Depois de 8 minutos, ele foi estrangulado e teve fim seu sofrimento.
} 
Foi absolutamente necessário constituir o povo como um sujeito moral, portanto separando-o da delinquência, separando nitidamente o grupo de delinquentes, mostrando-os como perigosos não apenas para os ricos, mas também para os pobres, mostrando-os carregados de todos os vícios e responsáveis pelos maiores perigos. Esse discurso sobre a criminalidade - ou, como prefere Foucault, o discurso da delinquência - vem sendo cristalizado desde o nascimento da literatura policial e da importância, nos jornais, das páginas policiais, das horríveis e detalhadas narrativas dos crimes.

A utilização dos estereótipos, neste sentido, acaba reforçando a imagem de um grupo anteriormente definido, em que características físicas ou o lugar onde se mora podem ser bem mais considerados do que informações sobre o caráter, a moral, os valores de cada indivíduo. Essa formação acontece muito mais no campo dos enunciados - o campo do discurso - do que na interpretação da realidade - uma vez que os bairros de delinquentes os separam do convívio, e ainda o excluem da realidade social e, consequentemente, dos meios de comunicação, responsáveis hoje por boa parte da disseminação de informações.

O discurso da criminalidade, ou discurso da delinquência, aparece bastante demarcado em $A$ Sangue Frio. Capote lança um novo olhar sobre o crime cometido por Dick e Perry, na medida em que não se limita a contar a vida da família vitimada, abrindo espaço para uma narrativa que também constitui os criminosos como sujeitos. O efeito dessa forma narrativa pode ser entendido como uma tentativa de contraponto ao próprio discurso da delinquência: na narrativa de A Sangue Frio, a forma como as situações se sucedem, a maneira como os personagens são apresentados, a presença dos elementos literários alternados desde o início da obra acabam por mudar significativamente os vetores de interesse, pertinência e reprodução do modelo.

A descrição que acompanha a narrativa sobre o trajeto dos jovens rumo ao seu destino mostra-se mais que pertinente, configura-se em essencial para a continuidade da narrativa. $\mathrm{O}$ modelo é abandonado, uma vez que a extensão do discurso presente no livro amplia a lente do estereótipo para penetrar na vida e na mente dos personagens. E há, ainda, espaço para demonstrar como o aparelho prisional é determinante na fabricação da delinquência, agindo diretamente sobre as intenções e as circunstâncias que acabam por proporcionar o desfecho da história.

Ao estabelecer uma abordagem dialética que mostra, de um lado, uma classificação representativa e de outro uma descrição particular dos indivíduos, o resultado é o que pode se chamar de texto aberto, em construção, que não se fecha em si mesmo e não encerra a história pelo que sabemos dela. O caráter de representatividade e de intertextualidade que se apresenta acaba por compor objetivamente uma linha narrativa lógica, coerente internamente e que ainda consegue apontar para fora do texto. 


\section{CONSIDERAÇÕES FINAIS}

O que pode ser facilmente inferido é que, na função de autor-narrador, Truman Capote tenha intensificado ainda mais os elementos narrativos de sujeição que já foram enunciados aqui, como por exemplo o discurso em torno da insegurança e do fatalismo aparente de Perry em oposição à suposta segurança e autossuficiência de Dick. Logicamente, as unidades de discurso simbólico utilizadas pelo autor devem caminhar neste mesmo sentido e nem poderia ser inferido de outra maneira.

Por diversas vezes há a sugestão de que Perry seria desequilibrado mentalmente, o que poderia ter provocado o movimento decisivo que acabou com a morte da família Clutter. Podemos observar, pelas credenciais dos dois jovens, que por mais dissimulado que Dick pareça, nenhuma de suas descrições comportamentais aponta para alguém capaz de cometer, sozinho, os crimes hediondos que se sucedem na narrativa. Ao contrário, em todas as descrições feitas, ele aparece como alguém capaz de cometer delitos menores, cheques sem fundo, pequenos calotes, vícios de quem passara a vida enganando aqui e ali.

O texto nos leva a acreditar que todo o planejamento do crime em si só teria eficácia mediante a frieza de seus autores, mas a execução sumária da família, o assassinato frio e trágico da família seria motivado por um elemento muito mais forte, mais representativo do que simplesmente cumprir o plano. O que leva à situação extrema do assassinato não é, com certeza, levar a cabo o ato planejado, mas uma medida drástica a partir de algo que foge do controle, mas que seria possível de ser cometido por alguém desafiado, instigado, provocado ao seu limite máximo de tensão.

O sujeito que aparentemente se constitui na narrativa já está constituído a priori. O que acontece, com efeito, é a revelação do sujeito à luz da situação que se lhe é dada. Foucault (1969) já havia adiantado, em As palavras e as coisas, que na epistémê da representação o tempo funciona como pano de fundo do conhecimento, enquanto que o espaço ocupa o primeiro plano. Ora, quem é o sujeito que acontece neste interregno, entre o pano de fundo do conhecimento, e o primeiro plano do espaço? É alguém que certamente já conhecemos, mas que nos é dado a uma nova forma de o conhecer. É um sujeito capaz de realizar o ato que se conta nas próximas páginas e é a partir da narrativa que esse conhecimento se materializa.

Através dos tempos, os observadores têm focado sua investigação em dois aspectos, quando se analisam os escritos autobiográficos dos criminosos: ou são utilizados para verificar um suposto desequilíbrio mental capaz de modificar o diagnóstico sobre a sanidade, ou configuram-se como uma espécie de confissão, ainda que não sejam abordados em qualquer momento o crime em si ou a escala de culpabilidade dos acusados. Ao serem analisadas as condições sociais dos sujeitos, a infância, as relações com a família, o que pensam, como se relacionam com o mundo e, principalmente, como reagem frente a determinadas situações, os escritos autobiográficos acabam sendo muito mais um 
documento utilizado para o julgamento dos indivíduos do que para um melhor conhecimento a respeito dos indivíduos. Isso porque a observação centra-se apenas nos atos e nas circunstâncias em que esses atos foram constituídos e negligencia os sujeitos em formação nestes próprios procedimentos de escrita e, por extensão, nos enunciados que os constituem como sujeitos a partir de uma histórica relação social de poder. 


\section{REFERÊNCIAS BIBLIOGRÁFICAS}

CAPOTE, T. A Sangue Frio. São Paulo: Abril Cultural, 1980.

DELEUZE, G. Foucault. São Paulo: Brasiliense, 1988.

FOUCAULT, M. Arqueologia do saber. 7. ed. Rio de Janeiro: Forense Universitária, 2004b. . Microfísica do Poder. Rio de Janeiro: Graal, 1979

Janeiro: Vozes, 2004. Trad. VASSALO; Ligia M. Ponde. Vigiar e Punir: nascimento da prisão. Rio de

HARRER, Sebastian. The theme of subjectivity in Foucault's lecture series L'Hermeneutique du Sujet. In: Foucault Studies, nº 2, p. 75-96. Bonn, Bonn University, 2005.

LUCÁKS, G. Narrar ou descrever? Rio de Janeiro: Civilização Brasileira, 1965.

REVEL, J. Michel Foucault: conceitos essenciais. Trad. Maria do Rosário Gregolin, Nilton Milanez, Carlos Piovesani. São Carlos: Claraluz, 2005.

WOLFE, Tom. Radical chique e o Novo Jornalismo. Trad. José Rubens Siqueira; posfácio de Joaquim Ferreira dos Santos. São Paulo: Companhia das Letras, 2005. 